\author{
Dean A. McManus \\ University of Washington, Seattle, Washington USA
}

\title{
WHAT DO STATISTICS ON GRADUATE EDUCATION IN OCEANOGRAPHY TELI US?
}

Every two years since 1978 the academic deans at ocean science graduate schools in the U.S.A. have met at an Ocean Science Educators' Retreat (OSER), where they have shared information on graduate study in oceanography. The deans represent the ten members of the Joint Oceanographic Institutions (JOI) and other interested oceanographic institutions. I'll refer to the group of 10 as the JOI schools and all institutions combined (some 25 institutions) as the OSER schools. In 1995, the Consortium for Oceanographic Research and Education (CORE) became the coordinating body for OSER and since 1995 has collected the data on graduate study with a standardized survey. Some of the data are summarized on line at CORE (http://core.cast.msstate.edu/oserintro.html).

I was asked by The Oceanography Society Council to examine the data. Looking at the data since 1995, I found certain data particularly interesting. The data, however, do have serious limitations, which result from changes in the base population. For instance, the ten JOI schools account for $50-60 \%$ of all the oceanography graduate students, but since 1995, first one and, since 1998, now two JOI schools no longer share all their information on graduate study, thus altering the statistical base. Nevertheless, the most obvious pattern in the data for both the OSER schools and JOI schools is the peak enrollment around 1995 of oceanography graduate students in residence and the irregular decrease in numbers through 1999, the most recent data. That the enrollment peaked is not extraordinary. According to the National Science Foundation's (NSF) Science and Engineering Indicators-2000, the graduate enrollment in science and engineering in the U.S.A. peaked in 1993 and has declined since then to 1997, their most recent data. Graduate enrollment in the natural sciences (physical, earth, and life sciences) peaked in 1994. The peak in oceanography enrollment was about the same time. As NSF notes, these downward trends in number of graduate students result from fewer undergraduate students wanting to undertake graduate study in science. Oceanography is no excep- tion. The total number of applications to graduate school at the OSER schools plummeted from 3063+ in 1996 to 2047 in 2000, a decrease of one-third. What are the faculties at oceanography graduate schools doing to change the minds of undergraduate students? Can they afford to say it's not their problem? Are they, perhaps, sharing their latest research results with their undergraduate and K-12 colleagues in order to help those colleagues better engage student interest in the ocean? Or do we need more oceanography graduate students, anyway?

The enrollment status of traditionally underrepresented groups caught my attention. These data are recorded as a percentage of the total population, as is normal, but for women oceanography graduate students the percentage statistics are misleading. You see, the percent of women among graduate students in residence at the OSER schools reporting increased from $37 \%$ in 1995 to $52 \%$ in 1998, dipping to $48 \%$ in 1999 , and rising to $52 \%$ again in 2000 . Commendable as this increase in percentage is, it is an increasing percentage of a decreasing total number and therefore less cause for commendation than it appears. The total number of women students has merely fluctuated by less than 100 between 1995 and 1999, while the total number of male students was dropping by 300 , hence the increase in percentage of women students. By contrast, the total number of women graduate students in science has continuously increased from 1975 to 1997 , the most recent NSF data. A more meaningful statement about women oceanography graduate students is that perhaps the number is now fluctuating about a stable mean. We can draw encouragement, however, from the increase since 1997 in the number of applications to graduate school by women and the corresponding increase in enrollment of new women students. From fall 1997 to fall 1999 applications by women increased from 971 to 1134 and new enrollment of these women increased from 180 to 211, even though the total number of women in residence dropped from 798 to 745 . Our small success in attracting women to graduate 
study in oceanography is no cause for complacency. In fact, the drop in number of women in residence may not be accounted for by degrees granted each year, in which case the increases in new enrollment of women may be more than offset by women dropping out of graduate study. We need to know whether they are, and if they are, why? What's wrong?

The percentage of traditionally underrepresented minorities (Asian/Pacific Islander, African-American, Hispanic, and American Indian/Alaskan Native) among oceanography graduate students has fluctuated between 4\% and 6\% for the OSER schools from 1995 to 2000. This is a lower percentage than for the natural sciences as a whole. According to the NSF data for 1997 , the most recent data, the total number of graduate students in the natural sciences was 114,697 , and the number of traditionally underrepresented minorities was 14,379 , or $12.5 \%$. Although the NSF Directorate for Geosciences and the U.S. Office of Naval Research are funding efforts to increase the participation of underrepresented groups in oceanography education, much more effort is needed from the schools, particularly when that $4-6 \%$ participation is woefully contrasted with the $40 \%$ of the college age population that will be represented by these groups by the end of this decade.

A decreasing number of applications to graduate school naturally raises the question whether the "quality" of the students is decreasing, too. I leave the answer to the individual graduate faculty member. Each must satisfy himself or herself, because the usual "measure" of quality, the Graduate Record Examination (GRE) score, is overrated. As an article by Peter Sacks in The Chronicle of Higher Education for 8 June 2001 reminds us, several statistical analyses of GRE scores have all concluded that the GRE score is all but useless in predicting success in graduate school or in a career. Of greater concern than "quality" of applicants may be whether there is a connection between the decrease in number of graduate students and the increase in number of postdocs. Although the data are insufficient to settle the matter, the number of postdocs is indeed increasing slightly as the number of graduate students decreases. Perhaps if we had better data, the inverse relationship would vanish. But if the relationship is real, is it driven by the economics that a postdoc can require less faculty supervision than a graduate student for about the same, or even less, cost to the grant? Or is the situation an attempt to limit the number of Ph.D.s in oceanography by the method suggested recently for the biological sciences?

Finally, let's turn to employment. The most recent data on students who sought first positions in permanent employment are from a survey between May 1998 and May 2000. The data confirm that the oceanography
Master's degree provides a versatile education for various career paths, as shown by the roughly equal employment of the 272 students in federal agencies, commerce, state agencies, and universities or research institutions. Only 15 were unemployed (5.5\%). (Let's hear it for the Master's programs!) The Ph.D. degree, however, appears not to be so versatile. Of the 374 $\mathrm{Ph}$.D. recipients, 228 are in universities or research institutions, 40 in federal agencies, 37 in commerce, 11 in non-profit organizations, 5 in state agencies, 10 unemployed $(2.7 \%)$, and there are 43 who left the country or have other or unknown employment. It can be said that $60 \%$ of our Ph.D.s are hired by universities, but the classification "universities and research institutions" is an academic potpourri that includes research institutions as well as liberal arts colleges. If this category were divided into 1) graduate research universities and research institutions without undergraduate courses (where research dominates), and 2) universities and colleges with undergraduate courses (where teaching of undergraduates is part of faculty duties), how would the employment numbers divide? Are OSER graduate schools educating Ph.D.s mainly for OSER employment? Is the oceanography $\mathrm{Ph} . \mathrm{D}$. degree so restricted to preparation for academic research that most students are not prepared for positions outside research universities and institutions? Or do we not encourage those careers? Or is the degree more versatile than we think? According to a survey of the Earth and space science Ph.D. class of 1999 by the American Geophysical Union (http://agu.org/sci_soc/cpst/99Finalreport.PDF), more people earned their Ph.D. in oceanography than took positions in oceanography. Whether they took jobs outside oceanography voluntarily or not, they were prepared to be versatile. More detailed information on permanent employment of our Ph.D. students could answer these questions.

The statistics seem to tell us that graduate education in oceanography is healthy but in need of action by the OSER graduate schools to address certain issues. Further, the schools would benefit from the better perspective of more consistently reported data by all the schools. For the data we have, we should thank Sarah Schoedinger, Assistant Director for Education at CORE. I thank her for my access to the data and her helpful answers to my questions. 